\title{
Perioperative fluid administration and complications in emergency gastrointestinal surgery-an observational study
}

Anders W. Voldby ${ }^{1}$, Anne A. Aaen², Roberto Loprete ${ }^{3}$, Hassan A. Eskandarani², Anders W. Boolsen', Simon Jønck ${ }^{4}$, Sarah Ekeloef ${ }^{5}$, Jakob Burcharth ${ }^{5}$, Lau C. Thygesen ${ }^{6}$, Ann M. Møller ${ }^{7,8}$ and Birgitte Brandstrup ${ }^{1,8^{*}}$ (D)

\begin{abstract}
Background: The fluid balance associated with a better outcome following emergency surgery is unknown. The aim of this study was to explore the association of the perioperative fluid balance and postoperative complications during emergency gastrointestinal surgery.

Methods: We retrospectively included patients undergoing emergency surgery for gastrointestinal obstruction or perforation. A perioperative fluid balance of $2.5 \mathrm{~L}$ divided the cohort in a conservative and liberal group. Outcome was Clavien-Dindo graded complications registered 90 days postoperatively. We used logistic regression adjusted for age, sex, American Society of Anesthesiologists' classification, use of epidural analgesia, use of vasopressor, type of surgery, intraabdominal pathology, and hospital. Predicted risk of complications was demonstrated on a continuous scale of the fluid balance.
\end{abstract}

Results: We included 342 patients operated between July 2014 and July 2015 from three centers. The perioperative fluid balance was 1.6 L IQR [1.0 to 2.0] in the conservative vs. 3.6 L IQR [3.0 to 5.3] in the liberal group. Odds ratio of overall $2.6(95 \% \mathrm{Cl} 1.5$ to 4.4$), p<0.001$, and cardiopulmonary complications 3.2 ( $95 \% \mathrm{Cl} 1.9$ to 5.7$), p<0.001$, were increased in the liberal group. A perioperative fluid balance of $0-2 \mathrm{~L}$ was associated with minimal risk of cardiopulmonary complications compared to $1.5-3.5 \mathrm{~L}$ for renal complications.

Conclusion: We found a perioperative fluid balance above $2.5 \mathrm{~L}$ to be associated with an increased risk of overall and cardiopulmonary complications following emergency surgery for gastrointestinal obstruction or perforation. A perioperative fluid balance of $0-2 \mathrm{~L}$ was associated with the lowest risk of cardiopulmonary complications and 1.5$3.5 \mathrm{~L}$ for renal complications.

Keywords: Fluid therapy, Intestinal obstruction, Intestinal perforation, Intraoperative care, Postoperative complications

\footnotetext{
* Correspondence: bbrn@regionsjaelland.dk; bbrandstrup@hotmail.com We presented preliminary study results at the annually meeting at the Danish Surgical Society.

'Department of Surgery, Holbæk Hospital, part of Copenhagen University Hospitals, Smedelundsgade 60, 4300 Holbaek, Denmark

${ }^{8}$ Institute for Clinical Medicins, University of Copenhagen, Copenhagen, Denmark

Full list of author information is available at the end of the article
}

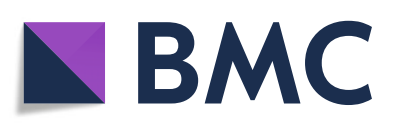

(- The Author(s). 2021 Open Access This article is licensed under a Creative Commons Attribution 4.0 International License, which permits use, sharing, adaptation, distribution and reproduction in any medium or format, as long as you give appropriate credit to the original author(s) and the source, provide a link to the Creative Commons licence, and indicate if changes were made. The images or other third party material in this article are included in the article's Creative Commons licence, unless indicated otherwise in a credit line to the material. If material is not included in the article's Creative Commons licence and your intended use is not permitted by statutory regulation or exceeds the permitted use, you will need to obtain permission directly from the copyright holder. To view a copy of this licence, visit http://creativecommons.org/licenses/by/4.0/. The Creative Commons Public Domain Dedication waiver (http://creativecommons.org/publicdomain/zero/1.0/) applies to the data made available in this article, unless otherwise stated in a credit line to the data. 


\section{Key points summary}

- We aimed to study the effect of a perioperative fluid balance above $2.5 \mathrm{~L}$ on postoperative complications following emergency gastrointestinal surgery.

- We found that a perioperative fluid balance above $2.5 \mathrm{~L}$ was significantly associated with an increased risk of overall- and cardiopulmonary complications and that the predicted risk of cardiopulmonary complications was at a minimum at a perioperative fluid balance between 0 and $2 \mathrm{~L}$ compared to 1.5$3.5 \mathrm{~L}$ for renal complications.

- Our results, from this multicenter observational study, imply a clinical potential of an optimized perioperative fluid strategy in patients undergoing emergency gastrointestinal surgery.

\section{Introduction}

Worldwide, more than 310 million patients undergo major surgery each year (Weiser et al., 2015). Mortality and complication rates are among the highest in patients undergoing emergency gastrointestinal surgery (Khuri et al., 2005; Tengberg et al., 2017). Perioperative intravenous fluid is given to replace fluid loss and to ensure the perfusion of the organs. However, escape to the extravascular space rapidly diminishes the circulatory effect. Interstitial edema may follow and counteract tissue oxygenation. Systemic sepsis and the trauma of surgery might further amplify the extravascular escape of intravenous fluids. Little is known about which fluid strategy that is associated with a better outcome during emergency gastrointestinal surgery.

Studies comparing a restrictive and a liberal fluid strategy in patients undergoing elective abdominal surgery have shown that a restrictive strategy reduces the risk of complications and length of hospital stay (Nisanevich et al., 2005; Abraham-Nordling et al., 2012; Lobo et al., 2002). Yet, a too restrictive fluid strategy may cause renal failure (Myles et al., 2017). A near zero-balance approach has been shown to reduce cardiopulmonary and tissue healing complications in elective abdominal surgery (Brandstrup et al., 2003). Based on these findings, programs of Enhanced Recovery After Surgery (ERAS) recommend a conservative perioperative fluid approach and a weight gain of no more than $2.5 \mathrm{~kg}$ (Feldheiser et al., 2016). Patients undergoing emergency gastrointestinal surgery may benefit from a similar restrictive perioperative fluid approach.

The pathophysiological differences between patients undergoing elective and emergency surgery are marked. Patients undergoing emergency surgery are usually older and have more co-morbidities, and postoperative complications and death are more frequent than in patients undergoing elective surgery (Ingraham et al., 2011; Becher et al., 2011). The perioperative fluid strategy is often challenged by preoperative deterioration of the patient. Periods with reduced fluid intake, excessive pathological fluid losses (e.g., vomiting), and a hyperinflammatory state call for careful attention when administering intravenous fluids (Becher et al., 2012). Sepsis may accompany the condition and fluid administration is a key element in the treatment. However, the volume associated with a better outcome is uncertain, especially for the surgical patient with sepsis (Rivers et al., 2001; Mouncey et al., 2015a; Investigators et al., 2014a; Investigators et al., 2014b).

We hypothesized that a perioperative liberal fluid strategy increases the risk of complications following emergency surgery for gastrointestinal obstruction or perforation. The aim of this cohort study was to compare the association of a conservative and a liberal fluid balance with postoperative complications following emergency surgery for gastrointestinal obstruction or perforation, and subsequently study the influence of the perioperative fluid balance on each type of complication.

\section{Methods}

Study approval was granted by the Danish Patient Safety Authority (3-3013-1999/1) and the Danish Data Protection Agency (REG-149-2016) prior to data extraction. Ethical approval for this study (J.nr. 16-000014) was provided by the Ethical Committee, Zealand Region, Denmark, on 14 December 2016. The requirement for written informed consent was waived by the committee. We retrospectively collected data on patients admitted between 1 July 2014 and 31 July 2015 at three teaching hospitals in the Region of Zealand, Denmark. The study sites offer treatment free of charge for a population of approximately 800,000 citizens. Local guidelines for intraoperative fluid administration during emergency gastrointestinal surgery were not present during the study period. The Strengthening the Reporting of Observational studies in Epidemiology (STROBE) statement was used in drafting this manuscript (von Elm et al., 2007).

We included all adult Danish residents undergoing emergency gastrointestinal surgery due to obstruction or perforation confirmed radiologically. Minor surgical procedures such as appendectomies, cholecystectomies, and endoscopic procedures were excluded. We defined emergency surgery as any intraabdominal procedure without planned delay. We excluded children (aged 17 years or younger), pregnant women, patients receiving regular dialysis, or patients with a traumatic or iatrogenic perforation. If eligible for inclusion, more than once patients were included only at the first procedure. We excluded patients who had had intraabdominal surgery 30 days prior to eligibility or patients without data on the intra- and postoperative fluid therapy. The 
Danish Civil Registration System provides uniform identification of every citizen through a personal identification number used to access all electronically stored medical and anesthetic records. It offers complete information on death for all Danish residents (Pedersen, 2011).

The primary exposure was the perioperative fluid balance starting from the induction of anesthesia and to the end of stay at the post-anesthetic care unit or the intensive care unit (ICU) for up to $24 \mathrm{~h}$. Fluid administration included crystalloids, glucose-containing fluids, colloids, intravenous drugs, packed blood products, and per oral intake. Fluid loss included diuresis, aspiration, emptied ascites, blood loss, and perspiration calculated as $0.5 \mathrm{~mL}$ $\mathrm{kg}^{-1} \mathrm{~h}^{-1}$. The fluid balance was calculated as the difference between the fluid administration and the fluid loss. Patients were divided in a conservative and liberal group at a perioperative fluid balance of $2.5 \mathrm{~L}$ in alignment with the ERAS recommendations (Ljungqvist et al., 2017).

The primary outcome was complications until postoperative day 90. The Clavien-Dindo classification (CDC) (Dindo et al., 2004) graded the complications and they were grouped into overall, wound-related, cardiopulmonary, renal, or infectious. We omitted CDC grade 1 because we expected nearly all patients to have a grade 1 complication. A complication graded $\mathrm{CDC} \geq 3$ was defined as a major complication and required radiological, endoscopic, or surgical intervention or critical care, which we defined as an admission at the intensive care unit. Secondary outcome was major complications or death at postoperative day 90 .

We registered the postoperative complications as follows: wound-related complications included superficial wound rupture, rupture of the fascia, or anastomotic leakage. Cardiopulmonary complications included cardiac arrhythmia, acute myocardial infarction, cardiac arrest, pleural effusion, pulmonary congestion, pulmonary edema, congestive heart failure, or respiratory failure (failure to wean $>48 \mathrm{~h}$, requiring continuous positive airway pressure after the day of extubating, or reintubation of any cause). Renal complications included the need for dialysis or other renal complications (nephritis or hydronephrosis treated with a nephrostomy catheter). Infectious complications included superficial wound infection, pneumonia, urinary tract infection, or cutaneous infection. A clinical doctor set the diagnosis and initiated medical treatment.

The three participating hospitals used identical software and uniform registration of variables. We screened the booking system for patients undergoing abdominal surgery. All emergency procedures meeting the inclusion criteria and unclassified cases were further explored. We accessed the medical and anesthetic records on each patient eligible for inclusion. The data collected preoperatively were physiological status, co-morbidities, sepsis-2 score, and American Society of Anesthesiologists' (ASA) classification. Intraoperatively, we registered the fluid administration and loss as specified above, vasopressor use and dose, hypotensive episodes defined as mean arterial pressure $<50 \mathrm{~mm} \mathrm{Hg}$ at any time intraand postoperatively, and the use of epidural analgesia.

Case report forms were used for data collection by our medically trained team. All team members were trained in the use of the Clavien-Dindo classification. AAA and AWV collected the anesthetic data, fluid administration, and losses. Two independent team members assessed each patient file and registered data on complications in two separate case report forms. Regular audit by the project leader (AWV) corrected irregularities. The senior advisor (BB) was consulted in case of incongruity. Database entry was conducted twice and inconsistencies were corrected by revisiting the case report form.

\section{Statistics}

Data were tested for normality and parametric or nonparametric statistics was used as appropriate. The primary outcome was analyzed with multiple logistic regression. Confounders included were settled between the authors and a statistician based on a priori knowledge of variables known to be associated with the fluid administration by the physician and the postoperative complications (Ford et al., 2007; Al-Temimi et al., 2012). We included sex, age, ASA class (grouped at I-II or III$\mathrm{V})$, use of epidural analgesia (yes or no), use of vasopressors (yes or no), the type of surgery performed (bowel resection, other procedure, or palliative surgery (exculpatory stoma formation or limited treatment)), the intraabdominal pathology (gastrointestinal obstruction or perforation), and the hospital (Holbæk, Slagelse, or Køge). Age was left skewed and the potency was used. In case of $>5 \%$ missing data of independent variables, multiple imputation was planned. We performed a subgroup analysis excluding patients with preoperative sepsis-2score $\geq 3$ or those admitted directly to the ICU after surgery. Additionally, we analyzed patients with major complications separately. The results are presented as odds ratio (OR) with $95 \%$ confidence interval $(95 \% \mathrm{CI})$. Statistically significance was Bonferroni corrected based on five outcomes, thus defined by a two-sided $p$-value < 0.01 . We presented the predicted risk of complications depending on the fluid balance on a continuous scale. A generalized additive model with smoothing splines and four degrees of freedom was used. The statistical plan was approved by the authors before commencing the analysis of data. The statistical software was $\mathrm{R}$ version 3.5.0 GUI 1.70 El Capitan@R, 2016 and RStudio version 1.1.453. 


\section{Results}

A total of 457 patients had emergency surgery with radiologically verified GI obstruction or perforation and were screened for inclusion. Of these, 342 patients were eligible for inclusion. Excluded were five patients because of pregnancy or age below 18 years, one had endstage renal failure, 65 patients had GI surgery within 30 days before the index procedure, fifteen had an iatrogenic perforation, nine patients had already been included once, eleven patients had trauma surgery, two patients were of foreign nationality, and seven patients were missing fluid data from the perioperative period.

A perioperative fluid balance of $2.5 \mathrm{~L}$ divided the cohort in two groups of similar size (Table 1). More patients in the liberal group had a gastrointestinal perforation (54 (33\%) vs. $30(17 \%))$. In agreement with this more patients in the liberal group had a preoperative sepsis score of 3-4 (36 (22\%) vs. $15(9 \%))$ and an ASA score of III-V (86 (53\%) vs. 69 (39\%)) and were more frequently admitted to the ICU directly following surgery (53 (33\%) vs. $15(8 \%))$.

During surgery, the liberal group had more hypotensive episodes, yet patients receiving vasopressor treatment were comparable between the groups. Postoperatively, more patients had hypotensive episodes and received vasopressors in the liberal group (Table 2). The median [IQR] perioperative fluid balance was $1.6 \mathrm{~L}$ [IQR 1.0 to 2.0 ] in the conservative group and $3.6 \mathrm{~L}$ [3.0 to 5.3 ] in the liberal group (Table 2). The liberal group were given more fluid intra- and postoperatively; however, the fluid loss increased primarily due to increase in diuresis.

\section{Primary outcome}

Altogether, 225 (65.8\%) patients had complications. The overall risk of complications was significantly associated with the liberal fluid group with an adjusted OR of 2.6 (95\% CI 1.5 to 4.4 ), $p<0.001$ (Table 3 ). No data were missing of the independent variables in the regression model. Subgroup analysis revealed a significantly increased risk of cardiopulmonary complications, OR: 3.2 (95\% CI 1.9 to 5.7 ), $p<0.001$ in the liberal group.

The association between the predicted risk of complications and the perioperative fluid balance on a continuous scale is presented in Figs. 1, 2, and 3 and Supplementary Figs. S1 and S2. The figures show that an increased perioperative fluid balance is associated with an increased risk of overall, cardiopulmonary, renal, infectious, or wound related complications. A U-shaped association between the perioperative fluid balance and the predicted risk of cardiopulmonary or renal complications is a good fit. The predicted risk of a cardiopulmonary complication is at a minimum at a perioperative fluid balance approximating $0-2 \mathrm{~L}$, whereas the minimal risk of renal complications is at a fluid balance approximating $1.5-3.5 \mathrm{~L}$.

\section{Major complications and death}

A total of 111 (32.5\%) patients developed a major complication $(C D C \geq 3)$. The risk of a major complication was not significantly associated with the liberal group (OR 1.6 (95\% CI 1.0 to 2.7), $p=0.077$ ) (Table 3). However, the association between the predicted risk of a major complications and the perioperative fluid balance on a continuous scale showed a U-shaped relation suggesting an optimal fluid balance of approximately 1-3 L (Supplementary Fig. S3). The overall risk of death was $25.4 \%$. The risk of death was not associated with the perioperative fluid balance.

\section{Sensitivity analysis}

We analyzed our data after excluding the 51 patients with a preoperative sepsis score of 3-4 and three patients of which data were missing. The risk of complications remained largely unchanged (Supplementary Table S1). Likewise, analyzing the data without the 68 patients admitted to the ICU immediately after surgery did not change the risk of complications (Supplementary Table 2 ). Of the patients admitted directly to the ICU after surgery, 31 had a preoperative sepsis score of 3-4 and 29 had postoperative hypotensive episodes of which 24 belonged to the liberal fluid group.

\section{Discussion}

Our study of patients undergoing emergency surgery for gastrointestinal obstruction or perforation showed a perioperative fluid balance of $3.6 \mathrm{~L}$ [IQR 3.0 to 5.3] compared with $1.6 \mathrm{~L}$ [IQR 1.0 to 2.0 ] to be significantly associated with a higher risk of postoperative complications, especially cardiopulmonary complications. The correlation remained robust after the exclusion of patients with preoperative severe sepsis or patients directly admitted at the ICU following surgery. The predicted risk of cardiopulmonary and major complications were at a minimum at a perioperative fluid balance of $0-2 \mathrm{~L}$, whereas the predicted risk of renal complications were at a minimum at a fluid balance of $1.5-3.5 \mathrm{~L}$.

A little is known about the influence of the perioperative fluid therapy on postoperative complications in patients undergoing emergency gastrointestinal surgery. One pilot study randomized 29 patients undergoing emergency abdominal surgery to two different fluid strategies (Harten et al., 2008). The perioperative fluid balance was $2.1 \mathrm{~L}$ vs $2.9 \mathrm{~L}$. No difference in renal function was found. In an early terminated study, 50 patients with severe sepsis undergoing mixed emergency surgery were randomized to two different goal directed fluid strategies (Pavlovic et al., 2016). The crystalloid 
Table 1 Baseline characteristics of the conservative or liberal fluid group of patients undergoing emergency gastrointestinal surgery

\begin{tabular}{|c|c|c|c|}
\hline & & $\begin{array}{l}\text { Conservative group (perioperative balance } \leq 2.5 \\
\text { L), number of patients (\%) }\end{array}$ & $\begin{array}{l}\text { Liberal group (perioperative balance }>2.5 \mathrm{~L} \text { ), } \\
\text { number of patients }(\%)\end{array}$ \\
\hline \multicolumn{2}{|l|}{ Number of patients } & 179 & 163 \\
\hline Sex & Female & $100(55.9)$ & $93(57.1)$ \\
\hline Age group & $\begin{array}{l}\text { Years (median } \\
(\text { IQR) }\end{array}$ & $70.0[57.5,79.0]$ & $72.0[66.0,79.0]$ \\
\hline \multirow[t]{2}{*}{ Body mass index } & Median (IQR) & $23.9[21.1,26.8]$ & $23.9[21.5,27.9]$ \\
\hline & Missing & 14 & 10 \\
\hline \multirow[t]{2}{*}{ Smoking habits } & Current smoker & $55(32.4)$ & $55(34.2)$ \\
\hline & Missing & 9 & 2 \\
\hline \multirow[t]{2}{*}{$\begin{array}{l}\text { Alcohol intake, } \\
\text { female/male }\end{array}$} & $\begin{array}{l}>7 />14 \text { units } \\
\text { week }^{-1}\end{array}$ & $15(8.7)$ & $24(15.5)$ \\
\hline & Missing & 7 & 8 \\
\hline \multirow[t]{2}{*}{ ASA classification } & $1-2$ & $110(61.5)$ & $77(47.2)$ \\
\hline & $3-5$ & $69(38.5)$ & $86(52.8)$ \\
\hline \multirow{3}{*}{$\begin{array}{l}\text { Sepsis-2 score, } \\
\text { preoperative }\end{array}$} & $0-2$ & $162(91.5)$ & $126(77.8)$ \\
\hline & $3-4$ & $15(8.5)$ & $36(22.2)$ \\
\hline & Missing & 2 & 1 \\
\hline \multirow[t]{7}{*}{ Co-morbidity ${ }^{\#}$} & Heart disease & $45(25.1)$ & $39(23.9)$ \\
\hline & Hypertension & $73(40.8)$ & $79(48.5)$ \\
\hline & $\begin{array}{l}\text { Pulmonary } \\
\text { disease }\end{array}$ & $26(14.5)$ & $31(19.0)$ \\
\hline & Liver disease & $10(5.6)$ & $5(3.1)$ \\
\hline & Renal disease & $11(6.1)$ & $15(9.2)$ \\
\hline & Diabetes mellitus & 19 (10.6) & $29(17.8)$ \\
\hline & $\begin{array}{l}\text { Active cancer } \\
\text { disease }\end{array}$ & $24(13.4)$ & $30(18.4)$ \\
\hline \multirow[t]{9}{*}{ Diagnosis } & Adhesions & $94(52.5)$ & $61(37.4)$ \\
\hline & Crohn disease & $3(1.7)$ & $2(1.2)$ \\
\hline & Diverticulitis & $13(7.3)$ & $15(9.2)$ \\
\hline & $\begin{array}{l}\text { Hernia, } \\
\text { strangulated }\end{array}$ & $7(3.9)$ & $7(4.3)$ \\
\hline & $\begin{array}{l}\text { Intraabdominal } \\
\text { cancer }\end{array}$ & $23(12.8)$ & $30(18.4)$ \\
\hline & Perforated ulcer & $12(6.7)$ & $15(9.2)$ \\
\hline & Arterial ischemia & $4(2.2)$ & $5(3.1)$ \\
\hline & Volvulus & $11(6.1)$ & $9(5.5)$ \\
\hline & Other* & $12(6.7)$ & 19 (11.7) \\
\hline \multirow[t]{2}{*}{ Surgical indication } & $\begin{array}{l}\text { Gastrointestinal } \\
\text { obstruction }\end{array}$ & $149(83.2)$ & $109(66.9)$ \\
\hline & $\begin{array}{l}\text { Gastrointestinal } \\
\text { perforation }\end{array}$ & $30(16.8)$ & $54(33.1)$ \\
\hline \multirow[t]{3}{*}{ Surgical procedure } & Bowel resection & $59(33.0)$ & $98(60.1)$ \\
\hline & Other procedure ${ }^{\S}$ & $102(57.0)$ & $49(30.1)$ \\
\hline & Palliative surgery ${ }^{\ominus}$ & $18(10.1)$ & $16(9.8)$ \\
\hline Laparoscopy & & $11(6.1)$ & $11(6.7)$ \\
\hline \multirow[t]{2}{*}{ Primary anastomosis } & Small bowel & $16(8.9)$ & $21(12.9)$ \\
\hline & Ileo-colic & $12(6.7)$ & $9(5.5)$ \\
\hline
\end{tabular}


Table 1 Baseline characteristics of the conservative or liberal fluid group of patients undergoing emergency gastrointestinal surgery (Continued)

\begin{tabular}{|c|c|c|c|}
\hline & & $\begin{array}{l}\text { Conservative group (perioperative balance } \leq 2.5 \\
\text { L), number of patients (\%) }\end{array}$ & $\begin{array}{l}\text { Liberal group (perioperative balance }>2.5 \mathrm{~L} \text { ), } \\
\text { number of patients }(\%)\end{array}$ \\
\hline & Colo-colic & $2(1.1)$ & $5(3.1)$ \\
\hline Time to surgery, hou & & & \\
\hline From hospital & $0-12 \mathrm{~h}$ & $67(37.4)$ & $71(43.6)$ \\
\hline & $>12 \mathrm{~h}$ & $111(62.0)$ & $92(56.4)$ \\
\hline & missing & 1 & 0 \\
\hline $\begin{array}{l}\text { From assessment } \\
\text { by surgeon }\end{array}$ & $\begin{array}{l}\text { Hour (median } \\
{\left[{ }_{[\mathrm{QQR}}{ }^{\varphi} \text { ) }\right.}\end{array}$ & $3.0[2.0,6.0]$ & $3.0[2.0,6.0]$ \\
\hline & Missing & 1 & 0 \\
\hline Time of surgery, med & an $[\mathrm{IQR}]$ & $1.6[1.1,2.3]$ & $2.3[1.6,3.3]$ \\
\hline & & 3 & 2 \\
\hline Time of anesthesia, $\mathrm{m}$ & edian [IQR] & $2.2[1.8,2.9]$ & $3.0[2.2,4.0]$ \\
\hline Immediate postopera & tive intensive care & $15(8.4)$ & $53(32.5)$ \\
\hline Sepsis-2 score, & $0-2$ & $137(76.5)$ & 89 (54.6) \\
\hline & $3-4$ & $38(21.2)$ & $72(44.2)$ \\
\hline & Missing & 4 & 2 \\
\hline
\end{tabular}

"Some patients have more than one co-morbidity. ${ }^{\varphi}$ Interquartile range. *Unclassified surgery on the small or large bowel. ${ }^{\S}$ Adhesiolysis, gastro-duodenorrhaphia, herniotomy, or peritoneal lavage. ${ }^{\ominus}$ Exculpatory stoma formation or limited treatment

administration was $5.6 \mathrm{~L}$ vs $5.9 \mathrm{~L}$, and a significant increase in cardiac complications was found in the "liberal" group, most likely due to the protocoled dobutamine administration. A recent randomized trial compared a pressure-guided (standard) with a flowguided (goal-directed) fluid strategy in major emergency gastrointestinal surgery. The fluid volumes given on the day of surgery was 3984 vs. $3130 \mathrm{ml}$ respectively. Apart from a longer hospital stay in the flow group, no difference in outcome between the groups was found (Aaen et al., 2021).

We divided the patients into two groups, a liberal and a restrictive, after the intravenous fluid volume given; however, the as discussed below, the terms are not well defined in the literature.

We found more cardiopulmonary complications in the patients given a liberal fluid therapy. The group also received more vasopressors postoperatively. The dominating drug given was norepinephrine, which for most parts was given in the intensive care unit. Even so, our result remained robust in the sensitivity analysis when excluding patients directly admitted to the intensive care unit. This indicates that cardiopulmonary complications are not related to the greater use of vasoactive drugs in the liberal group in our study.

We demonstrated a U-shaped correlation between the fluid balance and postoperative complications. This has previously been suggested in meta-analysis of studies comparing restrictive vs. liberal fluid strategies during elective abdominal surgery (Bundgaard-Nielsen et al.,
2009; Varadhan \& Lobo, 2010). Some studies show a positive result from a restrictive perioperative fluid strategy (Nisanevich et al., 2005; Lobo et al., 2002; Brandstrup et al., 2003) while others report no effect or even a negative effect of a restrictive perioperative fluid strategy (MacKay et al., 2006; Kabon et al., 2005; Holte et al., 2007). The varying results may relate to the circumstance that a restrictive perioperative fluid strategy in one study might resemble a liberal fluid strategy in another study and that different groups of complications are used as outcome (Kabon et al., 2005; Kalyan et al., 2013). In emergency surgery, no method exists to define fluid balance, and the patients are not in balance when arriving to the hospital. Central hemodynamic parameters to measure fluid responsiveness have been proposed as indicators for normovolemia, but superiority to this approach has not been shown.

Our results suggest that the risk of cardiopulmonary and renal complications is differently associated with the perioperative fluid balance. Findings were in agreement with a registry study of patients admitted for elective non-cardiac surgery. Shin and colleagues included 92,000 patients in the study and divided the group in quintiles according to the fluid administration. They found a perioperative fluid administration of $>2.7 \mathrm{~L}$ to be significantly associated with an increased risk of respiratory complications, acute kidney injury, and mortality at 30 days (Shin et al., 2017). Additionally, a too restrictive perioperative fluid administration of $\leq 0.9 \mathrm{~L}$ was associated with an increased risk of acute kidney 
Table 2 Perioperative fluid administration, losses, and associated variables during and after emergency gastrointestinal surgery

\begin{tabular}{|c|c|c|}
\hline & $\begin{array}{l}\text { Conservative group (perioperative balance } \leq 2.5 \mathrm{~L} \text { ), } \\
\text { median [IQR] or no. (\%) } \\
n=179\end{array}$ & $\begin{array}{l}\text { Liberal group (perioperative balance }>2.5 \mathrm{~L} \text { ), } \\
\text { median [IQR] or no. (\%) } \\
n=163\end{array}$ \\
\hline \multicolumn{3}{|l|}{ Intraoperative data } \\
\hline \multicolumn{3}{|l|}{ Fluid variables, $\mathrm{mL}$} \\
\hline iv ${ }^{\#}$ crystalloids & $1400[950,1830]$ & $2360[1600,3280]$ \\
\hline iv colloids & $0[0,0]$ & $0[0,500]$ \\
\hline iv glucose containing fluids & $0[0,0]$ & $0[0,0]$ \\
\hline iv blood products & $0[0,0]$ & $0[0,0]$ \\
\hline iv other fluids & $110[60,170]$ & $190[90,280]$ \\
\hline Total iv fluid administration & $1610[1120,2040]$ & $2750[2090,3750]$ \\
\hline $\begin{array}{l}\text { Total iv fluid administration } \\
\left(\mathrm{mL} \mathrm{kg}^{-1} \mathrm{~h}^{-1}\right)\end{array}$ & $9.8[7.5,12.7]$ & $13.3[9.0,18.2]$ \\
\hline Missing, no. & 3 & 0 \\
\hline Diuresis & $120[0,380]$ & $180[70,450]$ \\
\hline Blood loss & $0[0,130]$ & $100[0,400]$ \\
\hline Other loss & $110[70,420]$ & $120[80,260]$ \\
\hline Total loss & $490[140,1130]$ & $600[310,1130]$ \\
\hline Fluid balance & $930[570,1290]$ & $2030[1550,2790]$ \\
\hline Hypotensive episodes & $79(44.1)$ & $105(64.4)$ \\
\hline Vasopressor given & $156(87.2)$ & $152(93.3)$ \\
\hline Ephedrine, $\mathrm{mg}, n=118 / 100^{\S}$ & $20.0[10.0,30.0]$ & $17.5[10.0,30.0]$ \\
\hline $\begin{array}{l}\text { Norepinephrine, } \mathrm{mg}, n=10 / \\
40^{\S}\end{array}$ & $1.5[0.4,3.4]$ & $2.8[1.8,5.0]$ \\
\hline $\begin{array}{l}\text { Phenylephrine, mg, } n=94 \text { / } \\
112^{\S}\end{array}$ & $1.0[0.4,2.2]$ & $2.8[1.0,5.7]$ \\
\hline \multicolumn{3}{|l|}{ Postoperative data } \\
\hline \multicolumn{3}{|l|}{ Fluid variables, $\mathrm{mL}$} \\
\hline iv crystalloids & $720[400,1280]$ & $1900[1090,3170]$ \\
\hline iv colloids & $0[0,0]$ & $0[0,400]$ \\
\hline iv glucose & $0[0,0]$ & $0[0,230]$ \\
\hline iv blood products & $0[0,0]$ & $0[0,0]$ \\
\hline iv other fluids & $180[5,350]$ & $410[180,1190]$ \\
\hline Total iv fluid administration & $950[590,1510]$ & $2970[1710,5620]$ \\
\hline $\begin{array}{l}\text { Total iv fluid administration } \\
\left(\mathrm{mL} \mathrm{kg}^{-1} \mathrm{~h}^{-1}\right)\end{array}$ & $3.5[2.3,4.8]$ & $4.6[3.7,6.8]$ \\
\hline Missing, no. & 3 & 1 \\
\hline Diuresis & $140[0,500]$ & $530[110,1320]$ \\
\hline Blood loss & $0[0,0]$ & $0[0,0]$ \\
\hline Other loss & $140[80,280]$ & $340[140,770]$ \\
\hline Total loss & $270[110,830]$ & $970[270,2240]$ \\
\hline Fluid balance & $520[250,850]$ & $1750[1110,3110]$ \\
\hline Hypotensive episodes & $17(9.5)$ & $46(28.4)$ \\
\hline Missing, no. & 0 & 1 \\
\hline Vasopressor given & $22(12.3)$ & $71(43.8)$ \\
\hline Ephedrine, $\mathrm{mg}, n=6 / 13^{\S}$ & $15.0[10.0,20.0]$ & $10.0[10.0,20.0]$ \\
\hline $\begin{array}{l}\text { Norepinephrine, } \mathrm{mg}, n=12 / \\
47^{\S}\end{array}$ & $5.9[3.4,14.2]$ & $12.8[6.2,20.0]$ \\
\hline
\end{tabular}


Table 2 Perioperative fluid administration, losses, and associated variables during and after emergency gastrointestinal surgery (Continued)

\begin{tabular}{|c|c|c|}
\hline & $\begin{array}{l}\text { Conservative group (perioperative balance } \leq 2.5 \mathrm{~L} \text { ), } \\
\text { median [IQR] or no. (\%) } \\
n=179\end{array}$ & $\begin{array}{l}\text { Liberal group (perioperative balance }>2.5 \mathrm{~L} \text { ), } \\
\text { median [IQR] or no. (\%) } \\
n=163\end{array}$ \\
\hline $\begin{array}{l}\text { Phenylephrine, } \mathrm{mg}, n=9 / \\
19^{\S}\end{array}$ & $2.2[1.0,8.1]$ & $3.1[0.5,5.9]$ \\
\hline \multicolumn{3}{|l|}{ Perioperative fluid data } \\
\hline Epidural analgesia, no. (\%) & $77(43.0)$ & $70(42.9)$ \\
\hline Total iv fluid administration & $2610[2160,3310]$ & $6000[4290,8930]$ \\
\hline $\begin{array}{l}\text { Total iv fluid administration } \\
\left(\mathrm{mL} \mathrm{kg}^{-1} \mathrm{~h}^{-1}\right)\end{array}$ & $5.9[4.1,7.8]$ & $7.3[5.4,10.2]$ \\
\hline Missing, no. & 3 & 0 \\
\hline Total loss & $920[480,2000]$ & $1900[960,3350]$ \\
\hline Fluid balance, $\mathrm{mL}$ & $1580[1000,2040]$ & $3620[3020,5340]$ \\
\hline Fluid balance, $\mathrm{mL} \mathrm{kg}{ }^{-1} \mathrm{~h}^{-1}$ & $3.3[1.7,5.2]$ & $4.7[3.4,7.2]$ \\
\hline Missing, no. & 3 & 0 \\
\hline
\end{tabular}

${ }^{\#}$ Intravenous. ${ }^{5}$ The result is presented for those who received vasopressor or inotropic as specified by the $n=$ (conservative / liberal)

injury, thus suggesting a U-shaped correlation between the fluid administration and the incidence of complications. The study implies a more beneficial outcome in the group of patients receiving a perioperative fluid infusion of $6-7 \mathrm{~mL} \mathrm{~kg}^{-1} \mathrm{~h}^{-1}$. In similarity, we found a more favorable outcome of a perioperative fluid balance of 1.6 $\mathrm{L}$ comparable to a fluid administration of $5.9 \mathrm{~mL} \mathrm{~kg}^{-1}$ $\mathrm{h}^{-1}$ for overall and cardiopulmonary complications. Our data suggest that renal function might benefit from a greater fluid administration, and are supported by the study including the largest number of elective surgical patients randomized to a liberal versus restricted fluid strategy: more patients with renal failure were found in the restricted group. Noteworthy, the protocol for that trial did not recommend fluid administration to patients with postoperative oliguria (Myles et al., 2017).

The limitations of our study lay within the retrospective design. The baseline data suggest a possible bias by indication: more patients in the liberal group had gastrointestinal perforation with sepsis and a high ASA score. We chose to adjust for the ASA score. Severe sepsis and co-morbidities are both inherent in the ASA score and as such dependent variables. In addition, more patients in the liberal group had hypotensive episodes treated with IV-fluid and/or vasopressors. We accommodated this by adjusting for the use of vasopressors in the regression model. However, we did not distinguish between different vasoactive drugs, nor a single- versus continuous administration. Blood loss, hypotension, and sepsis are likely to prompt fluid administration but are also linked with increase in morbidity which challenge interpretation of study results (Vincent et al., 2002; Abbott et al., 2018; Mouncey et al., 2015b). However, the sensitivity analysis excluding the patients with preoperative severe sepsis did not change the result, and the difference in blood loss between the groups was minimal (Table 2). We did not register and include the anesthesia used in our analysis (McLean et al., 2015). The anesthetists from the participating hospitals use for most parts propofol, remifentanil, and if indicated rocuronium. Our fluid data relied on the intra- and immediate postoperative period, but not the preoperative or later postoperative period. This is in accordance with most studies in the field.

The strengths of our study are the detailed prospectively registered record-data of perioperative fluid administration. Our data included fluid given as iv-medicine which is often omitted in other studies. Further, double registration of the fluid data and complications was performed to ensure the completeness of available data and avoid misclassification of complications. We adjusted for known confounders influencing the fluid administration and the postoperative complications, further strengthening our findings. The multicenter design strengthens external validity of the study results. Yet, the design has inherent limitations and causal relations are for future trials to explore.

\section{Conclusion}

With reservations to the inherent limitations in the study design, we found a perioperative fluid balance above $2.5 \mathrm{~L}$ to be significantly associated with an increased risk of overall and cardiopulmonary complications following emergency surgery for gastrointestinal obstruction or perforation. The predicted risk of complications demonstrates a U-shaped correlation with the perioperative fluid balance. A perioperative fluid balance of $0-2 \mathrm{~L}$ was associated with the fewest cardiopulmonary 
Table 3 Logistic regression analysis on the association between the perioperative fluid balance and postoperative complications following emergency gastrointestinal surgery

\begin{tabular}{|c|c|c|c|c|c|c|}
\hline \multirow[t]{2}{*}{ Complication } & \multirow{2}{*}{$\begin{array}{l}\text { Conservative } \\
\text { group } \\
N=179 \\
\text { No. of } \\
\text { patients (\%) }\end{array}$} & \multirow{2}{*}{$\begin{array}{l}\text { Liberal } \\
\text { group } \\
N=163 \\
\text { No. of } \\
\text { patients } \\
\text { (\%) }\end{array}$} & \multicolumn{2}{|l|}{ Crude } & \multicolumn{2}{|c|}{ Adjusted analysis $^{\alpha}$} \\
\hline & & & OR $(95 \% \mathrm{Cl}) *$ & $p$ & OR $(95 \% \mathrm{Cl}) *$ & $p$ \\
\hline \multicolumn{7}{|l|}{ Primary outcome } \\
\hline Overall complications & $98(58.0)$ & $127(73.4)$ & $2.9(1.8-4.7)$ & $<0.001$ & $2.6(1.5-4.4)$ & $<0.001$ \\
\hline \multicolumn{7}{|l|}{ Subgroups of outcome } \\
\hline Wound-related & $39(23.1)$ & $48(27.7)$ & $1.5(0.9-2.5)$ & 0.105 & $1.6(0.9-2.7)$ & 0.123 \\
\hline Superficial wound rupture & 18 & 25 & & & & \\
\hline Rupture of the fascia & 20 & 20 & & & & \\
\hline Leakage of the anastomosis & 1 & 3 & & & & \\
\hline Cardiopulmonary & $45(26.6)$ & $89(51.4)$ & $3.6(2.3-5.7)$ & $<0.001$ & $3.2(1.9-5.7)$ & $<0.001$ \\
\hline Arrhythmia & 14 & 28 & & & & \\
\hline Acute myocardial infarction & 2 & 2 & & & & \\
\hline Cardiac arrest & 2 & 0 & & & & \\
\hline Pleural effusion & 9 & 17 & & & & \\
\hline Pulmonary congestion & 5 & 14 & & & & \\
\hline Pulmonary edema & 2 & 2 & & & & \\
\hline Respiratory failure & 11 & 26 & & & & \\
\hline Renal & $7(4.1)$ & $15(8.7)$ & $2.5(1.0-6.7)$ & 0.053 & - & - \\
\hline Need for dialysis & 2 & 3 & & & & \\
\hline Other renal ${ }^{\S}$ & 5 & 12 & & & & \\
\hline Infectious & $73(43.2)$ & $90(52.0)$ & $1.8(1.2-2.8)$ & 0.008 & $1.6(1.0-2.5)$ & 0.071 \\
\hline Wound infection & 14 & 12 & & & & \\
\hline Pneumonia & 35 & 65 & & & & \\
\hline Urinary tract infection & 18 & 11 & & & & \\
\hline \multirow[t]{2}{*}{ Other infections } & 6 & 2 & & & & \\
\hline & \multicolumn{6}{|c|}{ Major complications } \\
\hline \multicolumn{7}{|l|}{ Secondary outcome } \\
\hline Major complication & $46(27.2)$ & $65(37.6)$ & $1.9(1.2-3.0)$ & 0.005 & $1.6(1.0-2.7)$ & 0.077 \\
\hline \multicolumn{7}{|l|}{ Subgroups of outcome } \\
\hline Wound-related & $23(13.6)$ & $27(15.6)$ & $1.3(0.7-2.5)$ & 0.333 & $1.2(0.6-2.4)$ & 0.606 \\
\hline Superficial wound rupture & 3 & 4 & & & & \\
\hline Rupture of the fascia & 19 & 20 & & & & \\
\hline Leakage of the anastomosis & 1 & 3 & & & & \\
\hline Cardiopulmonary & $22(13.0)$ & $45(26.0)$ & $2.7(1.6-4.9)$ & 0.000 & $2.5(1.3-4.9)$ & 0.006 \\
\hline Arrhythmia & 1 & 3 & & & & \\
\hline Acute myocardial infarction & 4 & 2 & & & & \\
\hline Cardiac arrest & 2 & 2 & & & & \\
\hline Pleural effusion & 3 & 9 & & & & \\
\hline Pulmonary congestion & 0 & 0 & & & & \\
\hline Pulmonary edema & 2 & 4 & & & & \\
\hline Respiratory failure & 10 & 25 & & & & \\
\hline Renal & $5(3.0)$ & $12(6.9)$ & $2.8(1.0-8.9)$ & 0.061 & - & - \\
\hline
\end{tabular}


Table 3 Logistic regression analysis on the association between the perioperative fluid balance and postoperative complications following emergency gastrointestinal surgery (Continued)

\begin{tabular}{|c|c|c|c|c|c|c|}
\hline \multirow[t]{2}{*}{ Complication } & \multirow{2}{*}{$\begin{array}{l}\text { Conservative } \\
\text { group } \\
N=179 \\
\text { No. of } \\
\text { patients (\%) }\end{array}$} & \multirow[b]{2}{*}{$\begin{array}{l}\text { Liberal } \\
\text { group } \\
N=163 \\
\text { No. of } \\
\text { patients } \\
\text { (\%) }\end{array}$} & \multicolumn{2}{|l|}{ Crude } & \multicolumn{2}{|c|}{ Adjusted analysis $^{\alpha}$} \\
\hline & & & OR $(95 \% \mathrm{Cl}) *$ & $p$ & OR $(95 \% \mathrm{Cl}) *$ & $p$ \\
\hline Need for dialysis & 2 & 3 & & & & \\
\hline Other renal & 3 & 9 & & & & \\
\hline Infectious & $14(8.3)$ & $15(8.7)$ & $1.2(0.6-2.6)$ & 0.647 & $1.1(0.5-2.5)$ & 0.874 \\
\hline Wound infection & 10 & 3 & & & & \\
\hline Pneumonia & 4 & 12 & & & & \\
\hline Urinary tract infection & 0 & 0 & & & & \\
\hline Other infections & 0 & 0 & & & & \\
\hline Death at postoperative day 90 & $36(21.3)$ & $51(29.5)$ & $1.8(1.1-3.0)$ & 0.019 & $1.3(0.7-2.4)$ & 0.477 \\
\hline
\end{tabular}

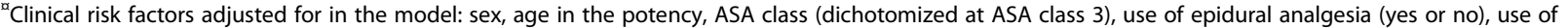
vasopressors (yes or no), the type of surgery (bowel resection, palliative surgery, or other procedures), gastrointestinal obstruction or perforation, and the Hospital (Holbæk, Slagelse, or Køge). ${ }^{*} O R$ odds ratio, 95\% Cl 95\% confidence interval. ${ }^{5}$ Hydronephrosis with nephrostomy catheter or treatment stalled due to renal failure. A $p$-value $<0.01$ is considered significant

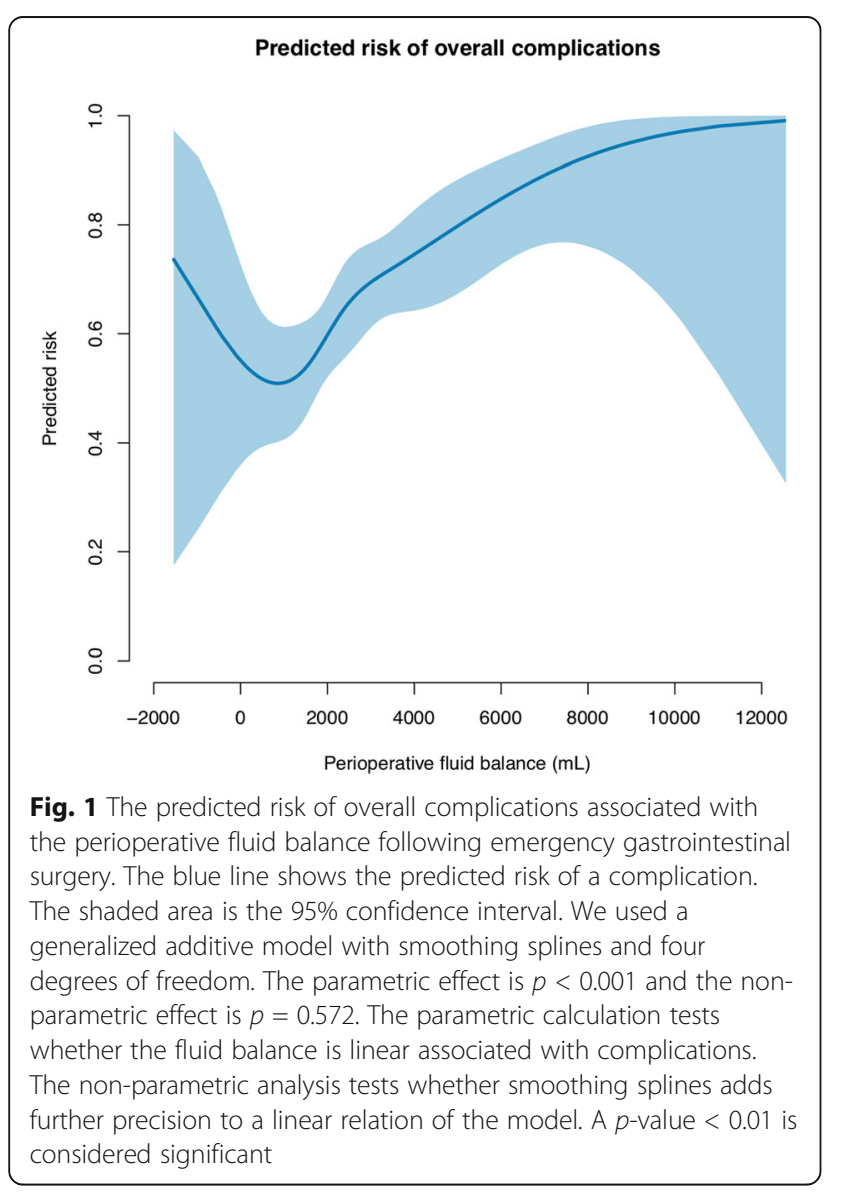

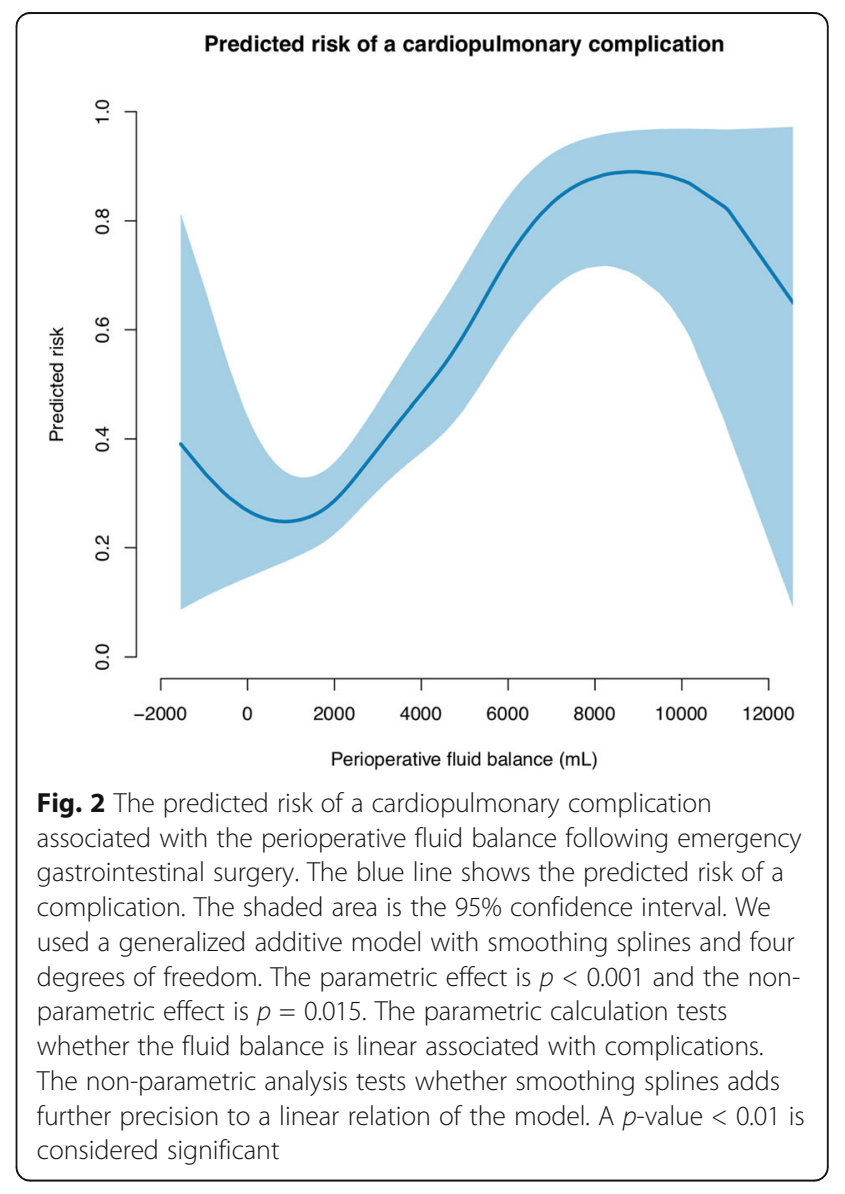




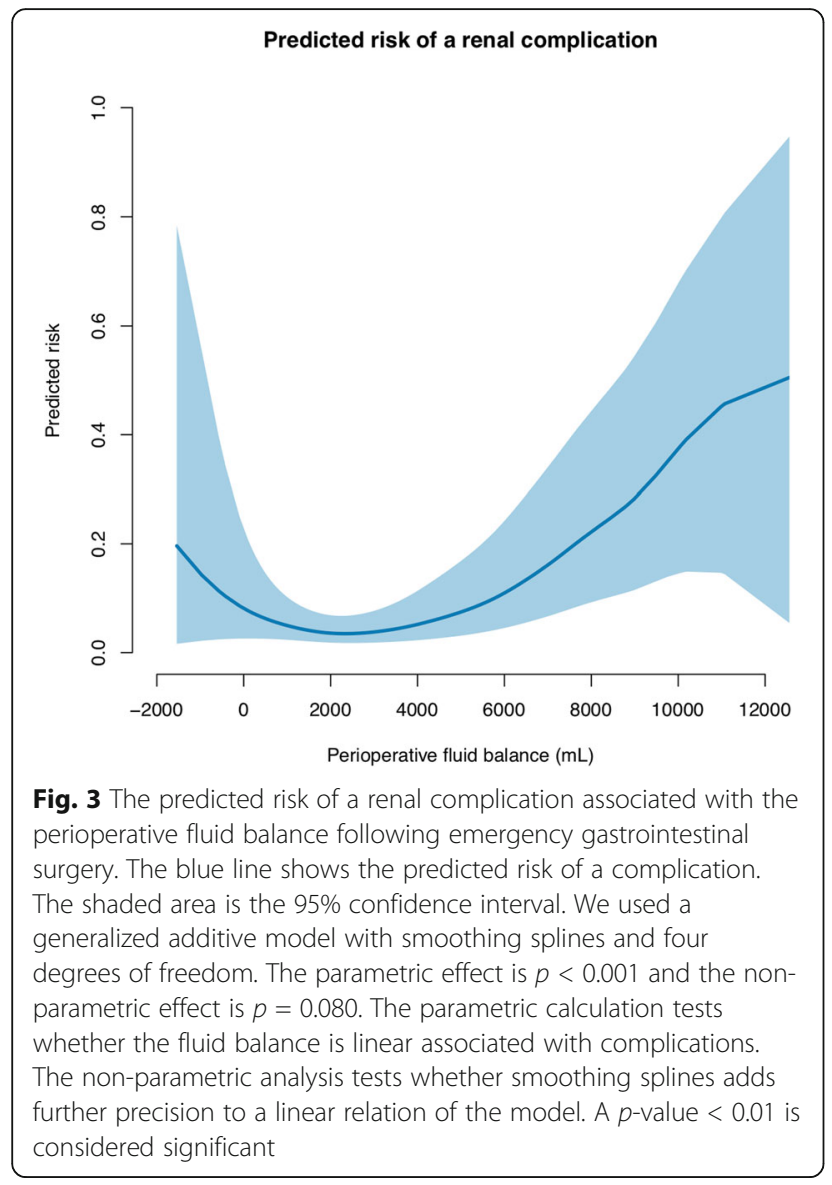

complications. The equivalent estimate was $1.5-3.5 \mathrm{~L}$ for renal complications. Our findings support our thesis that avoiding fluid overload in patients undergoing emergency gastrointestinal surgery may reduce the risk of complications.

\section{Abbreviations}

ASA: American Society of Anesthesiologists' physical status classification; CDC: Clavien-Dindo classification; Cl: Confidence interval; ICU: Intensive care unit; IQR: Interquartile range; OR: Odds ratio

\section{Supplementary information}

The online version contains supplementary material available at https://doi. org/10.1186/s13741-021-00235-y.

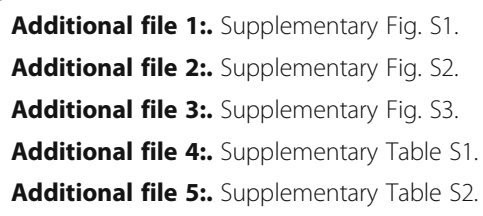

\section{Acknowledgements}

We are appreciative to Claus Juul, Chief Executive, Department of Surgery at Holbæk University Hospital; Mona Skarbye, Chief Executive, Department of Surgery at Slagelse University Hospital; and Ismael Gögenur, professor, Chief Executive, Centre for Surgical Science at University Hospital Zealand, for the acceptance of the collaborative work and making the presented project possible.

\section{Authors' contributions}

Anders Voldby: designed the idea, outlined the protocol, obtaining legislative and ethical approvals, planned the study, searched the literature, collected the data, planned and conducted the analysis, interpreted the results, drafted the present manuscript, and raised the funds. Anne Aaen: collected the data, revised the analysis and interpretation, and revised the manuscript. Jakob Burcharth: collected the data, revised the analysis and interpretation, and revised the manuscript. Sarah Ekeloef: collected the data, revised the analysis and interpretation, and revised the manuscript. Anders Boolsen: collected the data, interpreted the data, and revised the manuscript. Roberto Loprete: collected the data, interpreted the data, and revised the manuscript. Simon Jønck: collected the data, interpreted the data, and revised the manuscript. Hassan Eskandarani: collected the data, interpreted the data, and revised the manuscript. Lau Thygesen: planned the study, refined the drafted protocol, planned the analysis, supervised and revised the analysis and interpretation, and revised the manuscript. Ann Møller: planned the study, refined the drafted protocol, planned the analysis, supervised and revised the analysis and interpretation, and revised the manuscript. Birgitte Brandstrup: planned the study, refined the drafted protocol, planned the analysis, supervised and revised the analysis and interpretation, revised the manuscript, and raised the funds. All authors read and approved the fianl manuscript.

\section{Funding}

The Department of Surgery, Holbæk Hospital

The Trans-regional Fund between Zealand Region and The Region of South Denmark

The independent research unit of Zealand Region in Denmark

The Department of Anesthesiology and intensive care, Holbaek Hospital, part of Copenhagen University Hospitals

The Department of Anesthesiology and intensive care, Herlev University Hospital

Axel Muusfeldt's fund

Merchant Christian Andersen and wife Ingeborg Andersen's fund

The financial support to the project is unrestricted.

\section{Availability of data and materials}

Please contact the author for data requests.

\section{Declarations}

Ethics approval and consent to participate

Ethical approval for this study (J.nr. 16-000014) was provided by the Ethical Committee, Zealand Region, Denmark on 14 December 2016.

The requirement for written informed consent was waived by the committee.

Study approval was granted by the Danish Patient Safety Authority (3-30131999/1) and the Danish Data Protection Agency (REG-149-2016) prior to data extraction.

\section{Consent for publication}

Not applicable

\section{Competing interests}

The authors declare that they have no competing interests.

\section{Author details}

${ }^{1}$ Department of Surgery, Holbæk Hospital, part of Copenhagen University Hospitals, Smedelundsgade 60, 4300 Holbaek, Denmark. ${ }^{2}$ Department of Anesthesiology and Intensive Care Medicine, Holbæk Hospital, Holbæk, Denmark. ${ }^{3}$ Department of Surgery, Slagelse Hospital, Slagelse, Denmark. ${ }^{4}$ Department of Emergency Medicine, Holbæk Hospital, Holbæk, Denmark. ${ }^{5}$ Department of Surgery, Zealand University Hospital, Roskilde, Denmark. ${ }^{6}$ Department of Population Health and Morbidity, University of Southern Denmark, Odense, Denmark. ${ }^{7}$ Department of Anesthesiology and Intensive Care Medicine, Herlev Hospital, Herlev, Denmark. ${ }^{8}$ Institute for Clinical Medicins, University of Copenhagen, Copenhagen, Denmark. 
Received: 19 July 2021 Accepted: 11 November 2021 Published online: 22 February 2022

\section{References}

Aaen AA, Voldby AW, Storm N, Kildsig J, Hansen EG, Zimmermann-Nielsen E, et al. Goal-directed fluid therapy in emergency abdominal surgery: a randomised multicentre trial. Br J Anaesth. 2021;127(4):521-31. https://doi. org/10.1016/j.bja.2021.06.031.

Abbott TEF, Pearse RM, Archbold RA, Ahmad T, Niebrzegowska E, Wragg A, et al. A prospective international multicentre cohort study of intraoperative heart rate and systolic blood pressure and myocardial injury after noncardiac surgery. Anesth Analg. 2018;126(6):1936-45. https://doi.org/10.1213/ANE. 0000000000002560 .

Abraham-Nordling M, Hjern F, Pollack J, Prytz M, Borg T, Kressner U. Randomized clinical trial of fluid restriction in colorectal surgery. Br J Surg. 2012;99(2):18691. https://doi.org/10.1002/bjs.7702.

Al-Temimi MH, Griffee M, Enniss TM, et al. When is death inevitable after emergency laparotomy? Analysis of the american college of surgeons national surgical quality improvement program database. J Am Coll Surg. 2012;215(4):503-11. https://doi.org/10.1016/j.jamcollsurg.2012.06.004.

Becher RD, Hoth JJ, Miller PR, Meredith JW, Chang MC. Systemic inflammation worsens outcomes in emergency surgical patients. J Trauma Acute Care Surg. 2012;72(5):1140-9. https://doi.org/10.1097/TA.0b013e3182516a97.

Becher RD, Hoth JJ, Miller PR, Mowery NT, Chang MC, Meredith JW. A critical assessment of outcomes in emergency versus nonemergency general surgery using the American College of Surgeons National Surgical Quality Improvement Program database. Am Surg. 2011;77(7):951-9. http://www. ncbi.nlm.nih.gov/pubmed/21944366. https://doi.org/10.1177/0003134811 07700738.

Brandstrup B, Tønnesen H, Beier-Holgersen R, Hjortsø E, Ørding H, Lindorff-Larsen $\mathrm{K}$, et al. Effects of intravenous fluid restriction on postoperative complications: comparison of two perioperative fluid regimens: a randomized assessor-blinded multicenter trial. Ann Surg. 2003;238(5):641-8. https://doi.org/10.1097/01.sla.0000094387.50865.23.

Bundgaard-Nielsen M, Secher NH, Kehlet H. "Liberal" vs. "restrictive" perioperative fluid therapy--a critical assessment of the evidence. Acta Anaesthesiol Scand. 2009;53(7):843-51. https://doi.org/10.1111/j.1399-6576.2009.02029.x.

Dindo D, Demartines N, Clavien P-A. Classification of Surgical Complications. Ann Surg. 2004;240(2):205-13. https://doi.org/10.1097/01.sla.0000133083.54934.ae.

Feldheiser A, Aziz O, Baldini G, Cox BPBW, Fearon KCH, Feldman LS, et al. Enhanced Recovery After Surgery (ERAS) for gastrointestinal surgery, part 2: Consensus statement for anaesthesia practice. Acta Anaesthesiol Scand. 2016; 60(3):289-334. https://doi.org/10.1111/aas.12651.

Ford PNR, Thomas I, Cook TM, Whitley E, Peden CJ. Determinants of outcome in critically ill octogenarians after surgery: an observational study. Br J Anaesth. 2007;99(6):824-9. https://doi.org/10.1093/bja/aem307.

Harten J, Crozier JEM, McCreath B, Hay A, McMillan DC, McArdle CS, et al. Effect of intraoperative fluid optimisation on renal function in patients undergoing emergency abdominal surgery: a randomised controlled pilot study (ISRCTN 11799696). Int J Surg. 2008;6(3):197-204. https://doi.org/10.1016/j.ijsu.2008.03. 002.

Holte K, Foss NB, Andersen J, Valentiner L, Lund C, Bie P, et al. Liberal or restrictive fluid administration in fast-track colonic surgery: a randomized, double-blind study. Br J Anaesth. 2007;99(4):500-8. https://doi.org/10.1093/ bja/aem211.

Ingraham AM, Cohen ME, Raval MV, Ko CY, Nathens AB. Comparison of hospital performance in emergency versus elective general surgery operations at 198 hospitals. J Am Coll Surg. 2011;212(1):20-28.e1.

Investigators ARISE, ANZICS Clinical Trials Group, Peake SL, et al. Goal-directed resuscitation for patients with early septic shock. N Engl J Med. 2014b; 371(16):1496-506. https://doi.org/10.1056/NEJMoa1404380.

Investigators PCESS, Yealy DM, Kellum JA, et al. A randomized trial of protocolbased care for early septic shock. N Engl J Med. 2014a;370(18):1683-93. https://doi.org/10.1056/NEJMoa1401602.

Kabon B, Akça O, Taguchi A, et al. Supplemental intravenous crystalloid administration does not reduce the risk of surgical wound infection. Anesth Analg. 2005;101(5):1546-53. https://doi.org/10.1213/01.ANE.0000180217. 57952.FE.

Kalyan JP, Rosbergen M, Pal N, Sargen K, Fletcher SJ, Nunn DL, et al. Randomized clinical trial of fluid and salt restriction compared with a controlled liberal regimen in elective gastrointestinal surgery. Br J Surg. 2013;100(13):1739-46. https://doi.org/10.1002/bjs.9301.

Khuri SF, Henderson WG, DePalma RG, Mosca C, Healey NA, Kumbhani DJ, et al. Determinants of long-term survival after major surgery and the adverse effect of postoperative complications. Ann Surg. 2005;242(3):326-41; discussion 341-3. https://doi.org/10.1097/01.sla.0000179621.33268.83.

Ljungqvist O, Scott M, Fearon KC. Enhanced Recovery After Surgery: a review. JAMA Surg. 2017;152(3):292. https://doi.org/10.1001/jamasurg.2016.4952.

Lobo DN, Bostock K, Neal KR, Perkins AC, Rowlands BJ, Allison SP. Effect of salt and water balance on recovery of gastrointestinal function after elective colonic resection: A randomised controlled trial. Lancet. 2002;359:1812-8,

MacKay G, Fearon K, McConnachie A, Serpell MG, Molloy RG, O'Dwyer PJ. Randomized clinical trial of the effect of postoperative intravenous fluid restriction on recovery after elective colorectal surgery. Br J Surg. 2006;93(12): 1469-74. https://doi.org/10.1002/bjs.5593.

McLean DJ, Diaz-Gil D, Farhan HN, Ladha KS, Kurth T, Eikermann M. Dosedependent association between intermediate-acting neuromuscular-blocking agents and postoperative respiratory complications. Anesthesiology. 2015; 122(6):1201-13. https://doi.org/10.1097/ALN.0000000000000674.

Mouncey PR, Osborn TM, Power GS, Harrison DA, Sadique MZ, Grieve RD, et al. Trial of early, goal-directed resuscitation for septic shock. N Engl J Med. 2015b;372(14):1301-11. https://doi.org/10.1056/NEJMoa1500896.

Mouncey PR, Osborn TM, Power GS, Harrison DA, Sadique MZ, Grieve RD, et al. Protocolised Management In Sepsis (ProMISe): a multicentre randomised controlled trial of the clinical effectiveness and cost-effectiveness of early, goal-directed, protocolised resuscitation for emerging septic shock. Health Technol Assess (Rockv). 2015a;19(97):1-150. https://doi.org/10.3310/hta19970.

Myles P, Bellomo R, Corcoran T, Forbes A, Wallace S, Peyton P, et al. Restrictive versus liberal fluid therapy in major abdominal surgery (RELIEF): rationale and design for a multicentre randomised trial. BMJ Open. 2017;7(3):e015358. https://doi.org/10.1136/bmjopen-2016-015358.

Nisanevich V, Felsenstein I, Almogy G, Weissman C, Einav S, Matot I. Effect of intraoperative fluid management on outcome after intraabdominal surgery. Anesthesiology. 2005;103(1):25-32. https://doi.org/10.1097/00000542-2 00507000-00008

Pavlovic G, Diaper J, Ellenberger C, Frei A, Bendjelid K, Bonhomme F, et al. Impact of early haemodynamic goal-directed therapy in patients undergoing emergency surgery: an open prospective, randomised trial. J Clin Monit Comput. 2016;30(1):87-99. https://doi.org/10.1007/s10877-015-9691-x.

Pedersen CB. The Danish Civil Registration System. Scand J Public Health. 2011; 39(7_suppl):22-5.

Rivers E, Nguyen B, Havstad S, Ressler J, Muzzin A, Knoblich B, et al. Early GoalDirected Therapy in the Treatment of Severe Sepsis and Septic Shock. N Engl J Med. 2001;345(19):1368-77. https://doi.org/10.1056/NEJMoa010307.

Shin CH, Long DR, McLean D, et al. Effects of intraoperative fluid management on postoperative outcomes. Ann Surg. 2017;1.

Tengberg LT, Cihoric M, Foss NB, Bay-Nielsen M, Gögenur I, Henriksen R, et al. Complications after emergency laparotomy beyond the immediate postoperative period - a retrospective, observational cohort study of 1139 patients. Anaesthesia. 2017;72(3):309-16. https://doi.org/10.1111/anae.13721.

Varadhan KK, Lobo DN. A meta-analysis of randomised controlled trials of intravenous fluid therapy in major elective open abdominal surgery: getting the balance right. Proc Nutr Soc. 2010;69(4):488-98. https://doi.org/10.1017/ S0029665110001734.

Vincent JL, Baron J-F, Reinhart K, et al. Anemia and blood transfusion in critically ill patients. JAMA. 2002;288(12):1499-507. https://doi.org/10.1001/jama.2 88.12.1499.

von Elm E, Altman DG, Egger M, et al. Strengthening the reporting of observational studies in epidemiology (STROBE) statement: guidelines for reporting observational studies. BMJ. 2007;335(7624):806-8. https://doi.org/1 0.1136/bmj.39335.541782.AD.

Weiser TG, Haynes AB, Molina G, Lipsitz SR, Esquivel MM, Uribe-Leitz T, et al. Estimate of the global volume of surgery in 2012: an assessment supporting improved health outcomes. Lancet. 2015;385(3):201-209F. https://doi.org/1 0.1016/S0140-6736(15)60806-6.

\section{Publisher's Note}

Springer Nature remains neutral with regard to jurisdictional claims in published maps and institutional affiliations. 